Original Research Article

\title{
Non-prescription sale of antibiotics in pharmacies across Puducherry, India
}

\author{
Mohan Jaganathan ${ }^{1} *$, Vallish $\mathbf{B N}^{2}$, Brahadeesh Mayathevar ${ }^{2}$, Raj Kishore Mahato ${ }^{3}$
}

\begin{abstract}
${ }^{1}$ Associate Professor, ${ }^{2}$ Assistant Professor, ${ }^{3}$ Professor, Department of Pharmacology, Velammal Medical College Hospital and Research Institute, Anuppanadi, Madurai - 625009. India
\end{abstract}

Received: 09 November 2016 Accepted: 14 November 2016

\section{*Correspondence to:}

Dr. Mohan Jaganathan, Email: drmsg74@gmail.com

Copyright: () the author(s), publisher and licensee Medip Academy. This is an openaccess article distributed under the terms of the Creative Commons Attribution NonCommercial License, which permits unrestricted noncommercial use, distribution, and reproduction in any medium, provided the original work is properly cited.

\begin{abstract}
Background: Despite being illegal, non-prescription sales of antibiotics in India continue to be a major contributor to antibiotic abuse, which fosters antibiotic resistance.

Methods: Two trained actors simulated symptoms of acute gastroenteritis (AGE) and upper respiratory tract infections (URTI) in 60 pharmacies each randomly selected in the Union Territory of Pondicherry, India. The ease of obtaining antibiotics, any additional enquiries made by the pharmacies, and any additional advise given were noted.

Results: Only 33/120 pharmacies (27.5\%) declined to dispense antibiotics without prescription; all 33 were attached to a hospital or nursing home. The most frequently dispensed antibiotics for AGE and URTI were ciprofloxacin $(41.4 \%)$ and coamoxiclav $(41.3 \%)$ respectively. Out of the 87 pharmacies which dispensed antibiotics without prescription, the presence of additional symptoms and previous drug allergy were enquired by $20(22.9 \%)$ and $9(10.3 \%)$ pharmacies respectively. While over half of the pharmacies gave instructions regarding dose, duration and frequency of antibiotic consumption, none of the pharmacies provided information regarding adverse reaction profile of antibiotics. Non-pharmacological measures for symptomatic improvement were advised by $24 / 120$ pharmacies $(20 \%)$.

Conclusions: Non-prescription sales of antibiotics are unacceptably high in Pondicherry. Stricter implementation of the law and public awareness of the perils of inappropriate antibiotic usage are the need of the hour.
\end{abstract}

Keywords: Antibiotics, Acute gastroenteritis, Non-prescription usage, Pharmacies, Upper respiratory tract infection

\section{INTRODUCTION}

Antibiotic resistance is a major public health threat worldwide. A major contributor for the development of antibiotic resistance is the inappropriate usage of antibiotics for conditions where they are not required. Though doctors at times are to be blamed for this occurrence, a major source of such inappropriate usage is the non-prescription sales of antibiotics by pharmacies. This is a problem that is observed throughout the world, notable exceptions being Europe and North America, where outpatient antimicrobials are largely restricted to prescription-only use..$^{1-5}$ Notably, over $2 / 3^{\text {rd }}$ of antibiotic sales in the world is accounted for by outpatient use. ${ }^{3}$
Taking cognizance of the harm induced by antibiotic abuse, many countries have made it illegal to dispense antibiotics without a valid prescription signed by a doctor. Such a regulation is also in place in India in the form of Schedule $\mathrm{H}$ and Schedule $\mathrm{H} 1$ of the Indian Drugs and Cosmetics Act. ${ }^{6}$ However, the impact of such a regulation is not fully known.

This survey was undertaken to find out the extent of sales of antibiotics without an official medical prescription in Pondicherry, a Union Territory in India. 


\section{METHODS}

This cross-sectional observational study was undertaken in the city of Pondicherry, a Union Territory of India, between September 2013 and February 2014, after obtaining institutional ethics committee approval to the study protocol.

Commercial licensed pharmacies within Pondicherry were listed and categorised based on their address. A number was assigned to each of these pharmacies, and a computerized random number generator was used to select 125 pharmacies for inclusion in the study. After selection, the pharmacies were divided into two groups: the acute gastroenteritis (AGE) group, and the upper respiratory tract infection (URTI) group. For the purpose of this study, we ignored general stores which also had pharmacy wings within them, and selected pharmacies (either stand-alone or attached to hospitals / clinics / nursing homes) which only sold drugs.

Two actors were trained by physicians to simulate two different clinical cases: one was trained to simulate AGE, and the other to simulate URTI. The actors were trained to simulate symptoms in a convincing way so that the pharmacists believed in their complaints. A structured algorithm of dialogue was prepared for both these scenarios: the symptoms for URTI included fever, cough, and nasal discharge since 3 days, and the symptoms for AGE included loose stools since 2 days. After explaining the symptoms, the actors requested the pharmacists to dispense drugs to treat the condition. Two different levels of demand were used to obtain antibiotics from the pharmacies. Initially, the actor would ask for medications to get rid of his complaints ( $1^{\text {st }}$ level of demand). At this stage, if the pharmacist does not dispense an antibiotic, then the actor would frankly ask for the antibiotic $\left(2^{\text {nd }}\right.$ level of demand).

The actors were trained to observe whether the pharmacists enquired for additional symptoms and history of drug allergy before dispensing the antibiotic. After obtaining antibiotic, the actors were trained to observe whether the pharmacists provided:

1. Medication details (dose, duration and frequency of medication)

2. Adverse drug reaction (ADR) profile of the drug (including questioning for any previous drug allergy)

\section{Non-pharmacological advice for symptom resolution}

It was not revealed to the pharmacists at any time, even after the session was completed, that the actor was not a genuine patient, and that this was a study.

\section{RESULTS}

Using an online portal, we identified a total of 306 commercial licensed pharmacies within Pondicherry. ${ }^{7}$ Out of the 125 pharmacies selected for the study, 5 were closed, and thus a total of 120 pharmacies were included in the study. Out of these 120 pharmacies, 60 pharmacies each were designated as AGE group and URTI group.

Out of the total 120 pharmacies, only 33 (27.5\%) declined to dispense antibiotics without prescription from a doctor; all of these pharmacies were attached to a hospital/ clinic/ nursing home (Table 1). Antibiotics were dispensed without prescription to 41 cases of AGE $(68.33 \%)$ and 46 cases of URTI $(76.67 \%)$. Before dispensing the antibiotics, less than $1 / 4^{\text {th }}$ of pharmacies enquired for additional symptoms, and only around $10 \%$ of pharmacies enquired regarding previous history of drug allergy. While few pharmacies provided some instruction about dose $(58 / 87,66.6 \%)$, duration and frequency $(47 / 87,54 \%)$ of antibiotics, none of them gave any instruction about the ADR profile of the antibiotics. Finally, non-pharmacological measures such as oral rehydration salts (ORS) ingestion for AGE and steam inhalation for URTI was given only by 6 and 18 pharmacies respectively (a total of 24/120 pharmacies, $20 \%)$.

Table 1: Pattern of antibiotics dispensed by pharmacies.

\begin{tabular}{|c|c|c|c|}
\hline & $\begin{array}{l}\mathbf{A G E} \\
(\mathrm{n}=60)\end{array}$ & $\begin{array}{l}\text { URTI } \\
(n=60)\end{array}$ & $\begin{array}{l}\text { Total } \\
(\mathrm{n}=120)\end{array}$ \\
\hline Antibiotic dispensed & $41(68.3 \%)$ & $\begin{array}{l}46 \\
(76.6 \%)\end{array}$ & $\begin{array}{l}87 \\
(72.5 \%)\end{array}$ \\
\hline $\begin{array}{l}\text { Antibiotic dispensed } \\
\text { at } 1^{\text {st }} \text { level of } \\
\text { demand }\end{array}$ & $37(61.6 \%)$ & $\begin{array}{l}40 \\
(66.6 \%)\end{array}$ & $\begin{array}{l}77 \\
(64.1 \%)\end{array}$ \\
\hline $\begin{array}{l}\text { Antibiotic dispensed } \\
\text { at } 2^{\text {nd }} \text { level of } \\
\text { demand }\end{array}$ & $4(6.66 \%)$ & $6(10 \%)$ & $\begin{array}{l}10 \\
(8.3 \%)\end{array}$ \\
\hline $\begin{array}{l}\text { Antibiotic not } \\
\text { dispensed }\end{array}$ & $19(31.6 \%)$ & $\begin{array}{l}14 \\
(23.3 \%)\end{array}$ & $\begin{array}{l}33 \\
(27.5 \%)\end{array}$ \\
\hline $\begin{array}{l}\text { Enquiry regarding } \\
\text { additional symptoms }\end{array}$ & $8 / 41(19.5 \%)$ & $\begin{array}{l}12 / 46 \\
(26 \%)\end{array}$ & $\begin{array}{l}20 / 87 \\
(22.9 \%)\end{array}$ \\
\hline $\begin{array}{l}\text { Enquiry regarding } \\
\text { history of drug } \\
\text { allergy }\end{array}$ & $2 / 41(4.8 \%)$ & $\begin{array}{l}7 / 46 \\
(15.2 \%)\end{array}$ & $\begin{array}{l}9 / 87 \\
(10.3 \%)\end{array}$ \\
\hline $\begin{array}{l}\text { Instruction on dose } \\
\text { of antibiotic }\end{array}$ & $\begin{array}{l}21 / 41 \\
(51.2 \%)\end{array}$ & $\begin{array}{l}37 / 46 \\
80.4 \%)\end{array}$ & $\begin{array}{l}58 / 87 \\
(66.6 \%)\end{array}$ \\
\hline $\begin{array}{l}\text { Instruction on } \\
\text { duration and } \\
\text { frequency of } \\
\text { antibiotic }\end{array}$ & $15 / 41(36.6 \%)$ & $\begin{array}{l}32 / 46 \\
(69.5 \%)\end{array}$ & $\begin{array}{l}47 / 87 \\
(54 \%)\end{array}$ \\
\hline $\begin{array}{l}\text { Information about } \\
\text { ADR profile of } \\
\text { antibiotic }\end{array}$ & Nil & Nil & Nil \\
\hline $\begin{array}{l}\text { Non- } \\
\text { pharmacological } \\
\text { measures for } \\
\text { symptom resolution }\end{array}$ & $\begin{array}{l}6 / 60(10 \%) \\
(\mathrm{ORS})\end{array}$ & $\begin{array}{l}18 / 60 \\
(30 \%) \\
\text { (Steam } \\
\text { inhalation) }\end{array}$ & $\begin{array}{l}24 / 120 \\
(20 \%)\end{array}$ \\
\hline
\end{tabular}


AGE: Acute Gastroenteritis; URTI: Upper Respiratory Tract Infection; ADR: Adverse Drug Reaction; ORS: Oral Rehydration Salts

The pattern of antibiotics that were dispensed for each of the simulated case scenarios is depicted in table 2. The most frequently dispensed antibiotic for AGE and URTI simulations was ciprofloxacin and amoxicillin respectively.

\section{DISCUSSION}

AGE and URTI are to common clinical conditions which often are self-limiting and respond to symptomatic treatment. However, these two are also common conditions for which unnecessary antibiotic prescription has been recorded frequently. ${ }^{8,9} \mathrm{We}$ selected these two conditions for this study to evaluate the extent of nonprescription dispensing of antibiotics in a Union Territory in South India.

Table 2: Details of antibiotics dispensed by pharmacies and other observations.

\begin{tabular}{|lllll|}
\hline & AGE $(\mathbf{n = 4 1 / 6 0 )}$ & & URTI (n=46/60) & Number dispensed $(\%)$ \\
\cline { 2 - 5 } & Antibiotic & Number dispensed (\%) & Antibiotic & $19(41.3 \%)$ \\
\cline { 2 - 5 } $\begin{array}{l}\text { Pattern } \\
\text { of antibiotic } \\
\text { dispensing }\end{array}$ & Ofloxacin & $17(41.4 \%)$ & Amoxicillin + clavulanic acid & $11(23.9 \%)$ \\
\cline { 2 - 5 } & Ofloxacin+tinidazole & $9(21.9 \%)$ & Azithromycin & $8(17.3 \%)$ \\
\cline { 2 - 5 } & & $2(4.9 \%)$ & Levofloxacin & $4(8.7 \%)$ \\
\hline
\end{tabular}

AGE: Acute Gastroenteritis; URTI: Upper Respiratory Tract Infection

The therapeutic goal in the treatment of acute diarrhoeal illness is restoration of hydration, which is best done through oral electrolyte fluids, or intravenous fluids in case oral rehydration is not possible or contraindicated. Empirical antibiotic therapy has limited role, except in patients with fever and bloody diarrhoea or febrile diarrhoeal illness, symptoms persisting for $>1$ week, or immunocompromised status. ${ }^{8}$ In our study, we found that out of 41 pharmacies which dispensed antibiotics for AGE without prescription, only 8 (19.5\%) enquired for the presence of symptoms in addition to the '2-day diarrhea without fever' history as presented by the actors, and only $6 / 60(10 \%)$ pharmacies in the AGE group provided advice about oral rehydration.

The most common diagnosis in an otherwise healthy ambulatory adult presenting with symptoms of upper respiratory tract infection is acute bronchitis or viral infection, both of which are usually self-limiting and require symptomatic treatment. Many systematic reviews have concluded that current evidence supports limited or no clinical benefits of antimicrobial usage in this population. ${ }^{10}$ The role of antimicrobials in such a presentation is often limited to selected acute bronchitis patients with chronic obstructive pulmonary disease and asthma. ${ }^{9}$ In our study, we found that out of 46 pharmacies which dispensed antibiotics for URTI without prescription, only $12(26 \%)$ enquired for the presence of additional symptoms, and only $18 / 60$ (30\%) URTI pharmacies advised steam inhalation.

Out of the 87 pharmacies which dispensed antibiotics without prescription, 77 dispensed at the $1^{\text {st }}$ level of demand itself. The observation that 33 pharmacies declined to dispense antibiotic in the absence of a valid prescription should be interpreted with caution, because all these 33 pharmacies were attached to a hospital or a nursing home. While a decent proportion of pharmacies provided instructions regarding dose, duration and frequency of antibiotic consumption, very few pharmacies enquired about history of drug allergies, and notably, none of the pharmacies provided any information about the ADR profile of the antibiotic.

Antibiotics are listed under the Schedule $\mathrm{H}$ of the Indian Drugs and Cosmetics Act 1940, which restricts the legal dispensing of these drugs without a prescription. ${ }^{11}$ However, the results of the present study, clearly shows that most pharmacies in this geographical region fail to comply with regulation. A similar study reported in 2015 by Shet $\mathrm{A}$ et al suggests that a similar situation exists in Bengaluru, India, and perhaps throughout the country. ${ }^{12}$ To further limit the inappropriate dispensing of antibiotics without prescription, the Government of India has introduced Schedule $\mathrm{H} 1$ in the Indian Drugs and Cosmetics Act from Mar 1, 2014. ${ }^{6}$ However, how effective this will be is a question difficult to answer. Our study and the one by Shet et al were conducted before the Schedule H1 was introduced. Further studies are required to assess whether the situation has changed post the introduction of Schedule H1.

Despite the presence of strict regulations, it is repeatedly observed that pharmacies indulge in irresponsible dispensing. One prominent reason for this is the unawareness in the general population about the perils of antibiotic abuse. All-round efforts should be made to reduce the inappropriate usage of antibiotics in the 
interest of the general population. On the part of the Government, mechanisms should be introduced to assess the compliance of pharmacies to the law, and appropriate punitive actions should be incorporated for nonadherence. More importantly, the pharmacists and the general public should be made aware of the hazards of inappropriate usage of antibiotics for conditions which do not benefit at all from these drugs.

\section{CONCLUSION}

This study confirms that the sale of antibiotics without prescription for conditions such as AGE and URTI is unacceptably high across the union territory of Puducherry. Though Schedule H1 has been introduced to further limit inappropriate antibiotics, further studies are required to assess its impact. Wide-spread awareness campaigns about the perils of antibiotic abuse are the need of the hour.

\section{ACKNOWLEDGEMENT}

The authors wish to acknowledge the assistance of Mr. Durairaj and Mr. Chezian in data collection for the study.

\section{Funding: No funding sources}

Conflict of interest: None declared

Ethical approval: The study was approved by the Institutional Ethics Committee

\section{REFERENCES}

1. Bi P, Tong S, Parton KA. Family self-medication and antibiotics abuse for children and juveniles in a Chinese city. Soc Sci Med. 2000;50:1445-50.

2. Sturm AW, van der Pol R, Smits AJ, van Hellemondt FM, Mouton SW, Jamil B, et al. Over-the-counter availability of antimicrobial agents, self-medication and patterns of resistance in Karachi, Pakistan. J Antimicrob Chemother. 1997;39:543-7.
3. Llor C, Cots JM. The sale of antibiotics without prescription in pharmacies in Catalonia, Spain. Clin Infect Dis. 2009;48:1345-9.

4. Gebretekle GB, Serbessa MK. Exploration of over the counter sales of antibiotics in community pharmacies of Addis Ababa, Ethiopia: pharmacy professionals' perspective. Antimicrob Resist Infect Control. 2016;5:2

5. Morgan DJ, Okeke IN, Laxminarayan R, Perencevich EN, Weisenberg S. Non-prescription antimicrobial use worldwide: a systematic review. Lancet Infect Dis. 2011;11:692-701.

6. Hazra A. Schedule H1: Hope or hype? Indian J Pharmacol. 2014;46:361-2.

7. Hello Pondicherry.com. Medical Shops. Available at http://www.hellopondicherry.com/medicals.html. Last accessed 6th Nov 2016.

8. Zollner-Schwetz I, Krause R. Therapy of acute gastroenteritis: role of antibiotics. Clin Microbiol Infect. 2015;21:744-9.

9. Vinnard C, Linkin DR, Localio AR, Leonard CE, Teal VL, Fishman NO, et al. Effectiveness of interventions in reducing antibiotic use for upper respiratory infections in ambulatory care practices. Popul Health Manag. 2013;16:22-7.

10. Smucny J, Fahey T, Becker L, Glazier R, McIsaac W. Antibiotics for acute bronchitis. Cochrane Database Syst Rev. 2000;(4):CD000245.

11. Kotwani A, Holloway K. Access to antibiotics in New Delhi, India: implications for antibiotic policy. J Pharm Policy Pract. 2013;6:6.

12. Shet A, Sundaresan S, Forsberg BC. Pharmacy-based dispensing of antimicrobial agents without prescription in India: appropriateness and cost burden in the private sector. Antimicrob Resist Infect Control. 2015;4:55.

Cite this article as: Mohan $\mathrm{J}$, Vallish BN, Brahadeesh M, Mahato RK. Non-prescription sale of antibiotics in pharmacies across Puducherry, India. Int J Basic Clin Pharmacol 2016;5:2403-6. 